\title{
Diarrheagenic Pathogens in Polymicrobial Infections
}

\author{
Brianna Lindsay, ${ }^{1}$ T. Ramamurthy, ${ }^{1}$ Sourav Sen Gupta, Yoshifumi Takeda, Krishnan Rajendran, \\ G. Balakrish Nair, and O. Colin Stine
}

During systematic active surveillance of the causes of diarrhea in patients admitted to the Infectious Diseases and Beliaghata General Hospital in Kolkata, India, we looked for 26 known gastrointestinal pathogens in fecal samples from 2,748 patients. Samples from about one-third (29\%) of the patients contained multiple pathogens. Polymicrobial infections frequently contained Vibrio cholerae $\mathrm{O} 1$ and rotavirus. When these agents were present, some coinfecting agents were found significantly less often $\left(p=10^{-5}\right.$ to $\left.10^{-33}\right)$, some were detected significantly more often $(p=$ $10^{-5}$ to $10^{-26}$ ), and others were detected equally as often as when $V$. cholerae $\mathrm{O} 1$ or rotavirus was absent. When data were stratified by patient age and season, many nonrandom associations remained statistically significant. The causes and effects of these nonrandom associations remain unknown.

$\mathrm{T}$ he estimated worldwide death rate from diarrheal diseases is $\approx 2.2$ million deaths per year (1). Diarrheal infections may be caused by an array of bacterial, viral, or parasitic pathogens. Some cases have 1 single defined cause, others do not have any defined cause, and a substantial number (one third) are caused by multiple pathogens (2). Because each known diarrheal pathogen fulfills Koch's postulates and is capable of being the sole etiologic agent causing disease, multiple pathogens are not essential for causing disease. How additional pathogens cause and contribute to the disease process is unknown. The source of the multiple pathogens in a patient could simply result from multiple pathogens in an urban environment of crowded,

Author affiliations: University of Maryland Baltimore, Baltimore, Maryland, USA (B. Lindsay, O.C. Stine); and National Institute for Cholera and Enteric Disease, Kolkata, India (T. Ramamurthy, S. Sen Gupta, Y. Takeda, K. Rajendran, G.B. Nair)

DOI: 10.3201/eid1704100939 impoverished conditions. If the various pathogens occurred independently in cases of disease, then each pathogen in a polymicrobial infection would be expected to occur in proportion to its presence in all patients with severe diarrhea.

In Kolkata, India, a megacity with a population $>10$ million, many persons live in crowded urban slums. Medical attention is available at the Infectious Disease and Beliaghata General Hospital, which serves the population of Kolkata. To determine the extent of disease caused by various bacterial, viral, and parasitic pathogens of the gastrointestinal tract, the National Institute of Cholera and Enteric Disease is conducting a systematic survey of patients hospitalized for diarrhea at this hospital. Analyses conducted after 2 years of data collection revealed that approximately one-third (29\%) of patients had polymicrobial infections (2); an earlier report from that ongoing study indicated that the 3 parasites detected most often (in $73 \%$ of patients with polymicrobial infections) were Giardia lamblia, Entamoeba histolytica, and Cryptosporidium spp. (3). We used data from the same ongoing survey to identify gastrointestinal tract pathogens in the feces of patients with severe diarrhea and to examine the relationships between co-infections of Vibro cholerae $\mathrm{O} 1$ and rotavirus with other bacterial, viral, and parasitic pathogens.

\section{Methods}

Details of sample collection and microbiological analyses have been published (2). The protocol has been approved by the Institutional Review Board at the National Institute of Cholera and Enteric Disease. Briefly, fecal specimens were collected systematically from patients entering the hospital from November 2007 through

${ }^{1}$ These authors contributed equally to this article. 
February 2010. Of note, the previous study analyzed data through October 2009; however, the systematic sampling is still ongoing. The specimens were collected from every fifth patient with diarrhea on 2 randomly selected days each week. Only patients with diarrhea (defined by World Health Organization guidelines as passage of $\geq 3$ loose or liquid stools per day or more frequently than is normal for the person) were eligible for inclusion in the study. Samples were collected from an average of $5.6 \%$ of eligible patients.

Each patient contributed 1 sample, and each sample was tested for all 26 common diarrheagenic pathogens. Standard microbiological techniques were used to examine the samples. Samples were collected in McCartney bottles (using sterile catheters or rectal swabs) containing CaryBlair medium and examined (within 2 hours of collection) for bacterial, viral, and parasitic pathogens by a combination of conventional, immunologic, and molecular methods. The bacterial pathogens ( $V$. cholerae, $V$. parahaemolyticus, $V$. fluvialis, Campylobacter jejuni, Campylobacter coli, Salmonella spp., Shigella spp., and diarrheagenic Escherichia coli) were isolated from appropriate selective media and identified by standard biochemical tests. Species and subtypes were confirmed by serotyping (for $V$. parahaemolyticus, Shigella spp., and Salmonella spp.) with commercially available antiserum (Denka Seiken, Tokyo, Japan; BioRad, Marnes-la-Coquette, France) and by PCR (for $V$. cholerae [4], $V$. fluvialis [5], enterotoxigenic $E$. coli [ETEC, including heat-labile and heat-stable enterotoxin producers], enteropathogenic E. coli [EPEC, typical and atypical], enteroaggregative $E$. coli [EAEC] [6], enteroinvasive E. coli, and Shiga toxin-producing $E$. coli [7]). Rotavirus was detected by polyacrylamide gel electrophoresis and silver staining (8). Noroviruses (groups I [NVG1] and II [NVG2]), sapovirus, and astrovirus were detected by reverse transcription-PCR with random primers for reverse transcription and specific primers for PCR (9). Adenoviruses were detected by the commercially available RotaAdeno VIKIA Kit (bioMérieux, Marcy l'Etoile, France). All samples were screened by using a highly sensitive antigen capture ELISA (TechLab, Inc., Blacksburg, VA, USA) of G. lamblia, Cryptosporidium parvum, E. histolytica, and Blastocystis hominis.

To test for possible associations, we used the Fisher exact test to compare pairs of pathogens (1, both, or neither) with an independent assortment based on the overall frequency with which pathogens were detected. To establish criteria for statistical significance, we calculated $\mathrm{p}$ values, odds ratios (ORs), and $95 \%$ confidence intervals (CIs). Additional covariates were collected and examined for confounding and interaction. These included patient age, gender, residence, and religion and season of infection. Seasons were defined as summer (March-June), monsoon (July-October), and winter (November-February). All analyses were conducted by using SAS version 9.2 (SAS Institute, Cary, NC, USA).

\section{Results}

Fecal samples were submitted from 2,748 patients. Patient demographic characteristics are listed in Table 1. A large proportion (44\%) of patients were 15-45 years of age, $\approx 13 \%$ were $\leq 1$ year of age, $80 \%$ resided in urban areas, $74 \%$ were Hindu, and $25 \%$ were Muslim. The following pathogens were detected in at least 1 sample: adenovirus, Aeromonas spp., astrovirus, B. hominis, $C$. jejuni, C. parvum, EAEC, EPEC, ETEC, E. histolytica, G. lamblia, NVG1, NVG2, rotavirus, Salmonella spp., sapovirus, Shigella spp., V. cholerae O1, V. cholerae O139, $V$. cholerae non-O1, $V$. cholerae non-O139, $V$. parahaemolyticus, and $V$. fluvialis. No pathogens were

\begin{tabular}{|c|c|}
\hline Characteristic & Total, no. (\%) \\
\hline \multicolumn{2}{|l|}{ No. pathogens } \\
\hline 0 & $766(27.9)$ \\
\hline$\geq 1$ & 1,982 (72.1) \\
\hline 1 & $1,169(42.5)$ \\
\hline 2 & $589(21.4)$ \\
\hline 3 & $165(6.0)$ \\
\hline 4 & $44(1.6)$ \\
\hline 5 & $10(0.4)$ \\
\hline 6 & $5(0.2)$ \\
\hline \multicolumn{2}{|l|}{ Age group, $\mathrm{y}^{*}$} \\
\hline$\leq 1$ & $360(13.1)$ \\
\hline$>1-2$ & $233(8.5)$ \\
\hline$>2-5$ & $177(6.4)$ \\
\hline$>5-15$ & $243(8.8)$ \\
\hline$>15-45$ & $1,210(44.0)$ \\
\hline$>45$ & $525(19.1)$ \\
\hline \multicolumn{2}{|l|}{ Gender } \\
\hline$M$ & $1,482(53.9)$ \\
\hline $\mathrm{F}$ & $1,266(46.1)$ \\
\hline \multicolumn{2}{|l|}{ Residence } \\
\hline Urban & $2,226(81.0)$ \\
\hline Rural & $522(19.0)$ \\
\hline \multicolumn{2}{|l|}{ Religion } \\
\hline Hindu & $2,043(74.3)$ \\
\hline Muslim & $698(25.4)$ \\
\hline Christian & $5(0.2)$ \\
\hline Other & $2(0.1)$ \\
\hline \multicolumn{2}{|l|}{ Season } \\
\hline Nov-Feb & $890(32.4)$ \\
\hline Mar-Jun & $837(30.5)$ \\
\hline Jul-Oct & 1,021 (37.1) \\
\hline \multicolumn{2}{|l|}{ Feces } \\
\hline Watery & $2,080(75.7)$ \\
\hline Loose & $561(20.4)$ \\
\hline Bloody & $21(0.8)$ \\
\hline Mucoid & $15(0.5)$ \\
\hline Bloody and mucoid & $71(92.6)$ \\
\hline
\end{tabular}


detected in $766(28 \%)$ of the 2,748 samples (Table 1), but test results were positive for the other $72 \%$. One pathogen was found for 1,169(43\%) samples and multiple pathogens for $813(29 \%)$ (Table 1). The 2 most commonly detected pathogens were $V$. cholerae $\mathrm{O} 1$ and rotavirus, which were found in $24 \%$ and $22 \%$ of samples, respectively.

$V$. cholerae $\mathrm{O} 1$ was detected in 661 samples. $V$. cholerae was the sole pathogen in 379 samples; however, it was isolated along with another diarrheagenic pathogen from 282 samples. The co-infection of $V$. cholerae and rotavirus was highly significant $\left(\mathrm{p}=1.12 \times 10^{-33}\right)$. Co-infection with $V$. cholerae and rotavirus was $\approx 5$-fold less likely (OR $0.18,95 \%$ CI $0.13-0.25$; Figure, panel A) to occur among
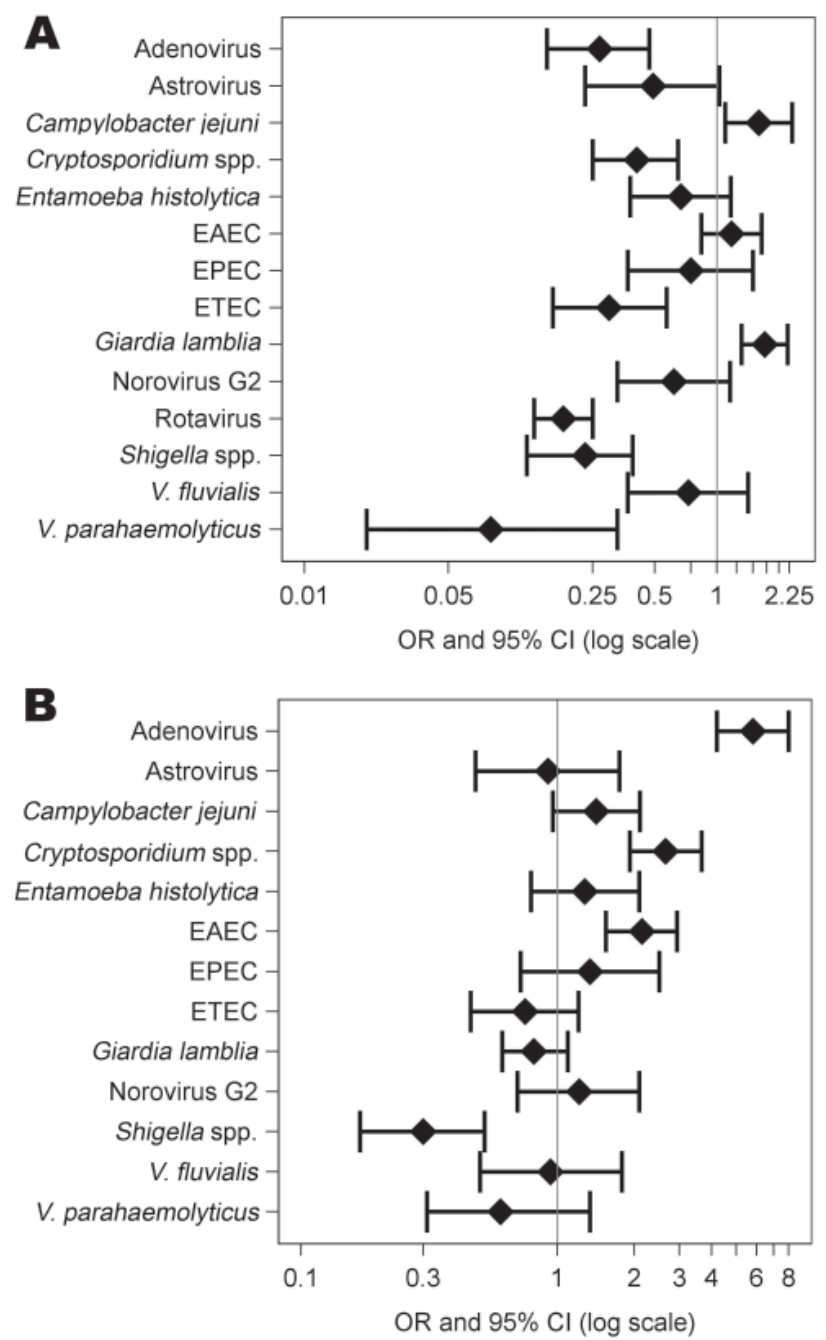

Figure. Odds ratios (ORs) showing odds of A) Vibrio cholerae or $B)$ rotavirus co-occurring with various other pathogens relative to the odds of $V$. cholerae or rotavirus co-occurring independently with various other pathogens at the frequency with which each is present in the entire sample. This standard forest plot indicates the best estimate and the $95 \%$ confidence intervals (Cls) for each co-occurring organism. EAEC, enteroaggregative Escherichia coli; EPEC, enteropathogenic E. coli; ETEC, enterotoxigenic E. coli. those with than among those without $V$. cholerae infection. A negative association might be expected if a case of severe diarrhea caused by any given pathogen excluded other pathogens. Consistent with this expectation, the presence of C. parvum, adenovirus, Shigella spp., ETEC, and $V$. parahaemolyticus was decreased significantly $\left(\mathrm{p}=7.87 \times 10^{-5}\right.$ to $\left.1.32 \times 10^{-9}\right)$ and was 12.5 -fold (with $V$. parahaemolyticus, OR $0.1,95 \% \mathrm{CI} 0.02-0.33$ ) to $2.44-$ fold (with C. parvum) less likely to occur among those with than among those without $V$. cholerae infection. However, antithetically, the rate of $G$. lamblia co-infection was significantly higher among $V$. cholerae O1-positive than among $V$. cholerae O1-negative fecal samples (OR 1.71, 95\% CI 1.32-2.21). A significant difference in infection rates among those with and without $V$. cholerae $\mathrm{O} 1$ infection was not found for EAEC, C. jejuni, V. fluvialis, E. histolytica, astrovirus, NVGII, and EPEC. Tests for association were not performed for Salmonella spp., NVGI, Aeromonas spp., B. hominis, $C$. coli, sapovirus, $V$. cholerae non-O1, $V$. cholerae non-O139, and $V$. cholerae O139 because the low number of patients infected with those pathogens resulted in insufficient power.

Rotavirus was detected in 594 of the fecal samples and was the sole pathogen found in 253 of them. Rotavirus and at least 1 other gastrointestinal pathogen were found in 341 samples; 119 samples were co-infected with rotavirus and $\geq 2$ other pathogens. When the effect of rotavirus co-infection with other pathogens was tested (Figure, panel B), Shigella spp. were significantly less likely to be found in samples with rotavirus than in samples without rotavirus (OR 0.30, 95\% CI 0.17-0.52). In contrast, EAEC, Cryptosporidium spp., and adenovirus were significantly increased in samples with rotavirus $\left(\mathrm{p}=6.15 \times 10^{-6}\right.$ to $1.61 \times 10^{-26}$; ORs 2.14-5.80. A significant effect was not observed for G. lamblia, C. jejuni, EPEC, ETEC, V. parahaemolyticus, $V$. fluvialis, E. haemolyticus, astrovirus, and NVGII. Tests for association were not performed for Salmonella spp., NVG1, Aeromonas spp., B. hominis, C. coli, sapovirus, $V$. cholerae non-O1, V. cholerae non-O139, and V. cholerae O139 because the low number of patients infected with those pathogens resulted in insufficient power. Analysis of samples from patients infected simultaneously with G. lamblia, V. cholerae, and rotavirus $(\mathrm{n}=41)$ revealed that the frequency of co-infection with G. lamblia was not significantly affected by co-infection with $V$. cholerae $\mathrm{O} 1$ and rotavirus $(\mathrm{p}=0.08)$.

Analysis of covariates indicated that gender, religion, and residence largely had no effect on the associations between pathogens; however, in some instances, age and season were identified as confounders or effect modifiers (Table 2). To examine the effect of these covariates, we stratified the data by age and season and found that many associations remained significant (online Appendix Table, 
Table 2. Effect of covariates on gastrointestinal pathogen associations*

\begin{tabular}{|c|c|c|c|c|c|c|}
\hline \multirow[b]{2}{*}{ Pathogens } & \multicolumn{6}{|c|}{ Covariate } \\
\hline & Age & Season & Gender & Residence & Religion & After adjusting for effects \\
\hline Vibrio cholerae/rotavirus & Confounder & Interaction & No effect & No effect & No effect & $\begin{array}{l}\text { Significant except for age } \\
\text { strata } 5-15 \text { y }\end{array}$ \\
\hline V. cholerae/adenovirus & Confounder & No effect & No effect & No effect & No effect & $\begin{array}{l}\text { Significant when regression } \\
\text { adjusted for age and season } \\
\text { (OR } 0.36,95 \% \mathrm{Cl} 0.21-0.64)\end{array}$ \\
\hline $\begin{array}{l}\text { V. cholerae/Cryptosporidium } \\
\text { spp. }\end{array}$ & Confounder & Confounder & Interaction & No effect & No effect & $\begin{array}{c}\text { Significant for female, not } \\
\text { male patients; small stratified } \\
\text { cell sizes }\end{array}$ \\
\hline V. cholerae/Giardia lamblia & Interaction & Confounder & No effect & Interaction & No effect & $\begin{array}{c}\text { Significant for some age } \\
\text { categories }\end{array}$ \\
\hline V. cholerae/Shigella spp. & Interaction & No effect & No effect & No effect & No effect & $\begin{array}{c}\text { Significant for ages }>2 \text { y and } \\
\text { all seasons }\end{array}$ \\
\hline V. cholerae/ETEC & No effect & Interaction & No effect & No effect & No effect & $\begin{array}{l}\text { Significant for summer and } \\
\text { monsoon seasons }\end{array}$ \\
\hline Rotavirus/adenovirus & Interaction & Interaction & No effect & No effect & No effect & $\begin{array}{l}\text { Significant for all seasons and } \\
\text { all age strata except }<1 \text { y }\end{array}$ \\
\hline $\begin{array}{l}\text { Rotavirus/Cryptosporidium } \\
\text { spp. }\end{array}$ & Confounder & Confounder & No effect & No effect & No effect & $\begin{array}{l}\text { Significant when regression } \\
\text { adjusted for age and season } \\
\text { (OR } 1.64,95 \% \mathrm{Cl} 1.11-2.41)\end{array}$ \\
\hline Rotavirus/EAEC & Confounder & No effect & No effect & No effect & Interaction & $\begin{array}{c}\text { Not significant when } \\
\text { regression adjusted for age } \\
\text { and season (OR 1.38, 95\% Cl } \\
0.94-2.01 \text { ); significant for age } \\
\text { strata 2-5 y; all seasons } \\
\text { significant }\end{array}$ \\
\hline Rotavirus/Shigella spp. & Confounder & Confounder & No effect & No effect & No effect & $\begin{array}{l}\text { Significant when regression } \\
\text { adjusted for age and season } \\
\text { (OR } 0.24,95 \% \mathrm{Cl} 0.14-0.44 \text { ) }\end{array}$ \\
\hline
\end{tabular}
interval; ETEC, enterotoxigenic Escherichia coli; EAEC, enteroaggregative E. coli.

www.cdc.gov/EID/content/17/4/606-appT.htm). Associations between rotavirus and adenovirus remained significant for all age and season strata except among children $\leq 1$ year of age. After adjusting for age and season by using logistic regression models, we found that co-infection with rotavirus and Cryptosporidium spp. and co-infection with rotavirus and Shigella spp. remained significant (Table 2). The negative association between $V$. cholerae and adenovirus remained significant after adjustment by logistic regression for age and season (OR 0.36; 95\% CI $0.21-0.64)$; associations between $V$. cholerae and many other pathogens remained significant within specific strata of age and season. Assessing the effect of covariates was limited in some instances because of small cell sizes. For this reason, we did not include stratified results for coinfection with $V$. cholerae and $V$. parahaemolyticus in the online Appendix Table.

\section{Discussion}

Our analyses revealed that co-occurrence of gastrointestinal pathogens in feces of patients with polymicrobial infections and severe diarrhea necessitating hospitalization was not in proportion to the pathogens' presence in all patients with diarrhea. Tests for association were performed with $V$. cholerae $\mathrm{O} 1$ and rotavirus because they were the most commonly detected pathogens and, hence, had the greatest power to detect an association with the other pathogens. Some combinations of pathogens occurred less frequently than expected (e.g., V. cholerae and rotavirus [OR $0.18,95 \%$ CI $0.13-0.25]$ ); some combinations appeared more frequently than expected (e.g., rotavirus and adenovirus [OR $=5.8,95 \%$ CI 4.20 7.99]), and some combinations occurred at the same frequency whether with or without $V$. cholerae or rotavirus. After adjustment for age and season, these variables often acted as confounders or effect modifiers, but in general the associations remained significant. However, many of the stratified analyses had small numbers for comparison.

$V$. cholerae $\mathrm{O} 1$ exhibited a positive association with only $G$. lamblia, suggesting that something may be unique about the co-occurrence of those 2 gastrointestinal pathogens. In support of that idea are 1) a report that coinfection with $G$. lamblia and $V$. cholerae results in $G$. lamblia being present in trophozoite form rather than in the cyst form found in feces of control patients (10), and 2) a previous finding that G. lamblia trophozoites can bind cholera toxin (11). Alternatively, each is a pathogen with substantial environmental reservoirs, and the positive association may simply represent acquisition of both pathogens from the same environmental source. 
Phylogenetic relatedness alone does not explain the apparent competitive inhibition or negative association that we found between $V$. cholerae and other pathogens. For example, although the closely related $V$. cholerae $\mathrm{O} 1$ and $V$. parahaemolyticus exhibited a 10 -fold negative association, $V$. fluvialis, which is phylogenetically only slightly farther from $V$. cholerae $\mathrm{O} 1$ than is $V$. parahaemolyticus, did not show any inhibition in the presence of $V$. cholerae. Also, although 2 members of the family Enterobacteriaceae (Shigella spp. and ETEC) were found less frequently than expected in combination with $V$. cholerae O1, 2 other members of that family (EPEC and EAEC) occurred in the expected proportion in samples from patients with mixed $V$. cholerae $\mathrm{O} 1$ infections.

Rotavirus had multiple strong positive associations $(\mathrm{ORs}>2)$ with the other gastrointestinal pathogens detected in the fecal samples, even after considering age and season. The positive association of rotavirus, an RNA virus that affects cells covered in microvilli, and adenovirus, a DNA virus that affects cells that are dividing to generate new cells with microvilli, may represent an interaction between pathogens to cause more severe diarrhea (in our sample all patients were hospitalized) in patients 15-45 years of age (OR 10.81, 95\% CI 5.63-20.78) or a way to escape or circumvent immunity from previous exposures. In a previous study, Koh et al. (12) found that among children in Korea with virus-caused diarrhea, adenoviruses occurred preferentially in the presence of rotavirus and that rotavirus and norovirus, although most common, occurred in polymicrobial infections in proportion to their numbers in the samples. Both observations are consistent with the results of our study. Furthermore, Bilenko et al. (13) observed that among Bedouins, G. lamblia was frequently found in polymicrobial infections and, when present with rotavirus, produced less severe diarrhea than rotavirus alone. In addition, Souza et al. (14) found that among young children in São Paulo, those with rotaviral and bacterial co-infections were more likely to have severe diarrhea than were children infected with either pathogen alone. However, the study had insufficient power to examine differences among bacterial pathogens, as did the rest of the studies of rotavirus infections mentioned in a recent review (15).

The presence of multiple pathogens in one third of patients with diarrhea has potential implications for treatment and raises several questions. Do cases of diarrhea caused by $V$. cholerae or rotavirus and a second pathogen differ from those caused by $V$. cholerae or rotavirus alone? Does 1 pathogen lead the way for another to successfully infect a person? Do the pathogens behave synergistically to escape immunologic detection? Because the crosssectional nature of our study did not enable us to investigate the temporal sequence of pathogen infection, future research is needed to provide more evidence concerning the causal pathway(s). Also, the clinical significance of our findings must be more rigorously evaluated by studies that include infected patients and controls. A more substantive investigation into how age and season might affect polymicrobial infections should also be conducted.

The results of our current study indicate that associations can occur between some pathogens affecting the human gastrointestinal tract. The observation of selective positive associations among some gastrointestinal pathogens raises the question of how they interact in vivo; e.g., is the critical factor a modification of gastrointestinal tract microflora? Understanding the association(s) among various co-infecting pathogens may help direct the development of treatment strategies.

Funding for this study was provided by The Ministry of Education, Culture, Sports, Science and Technology of Japan; the Indian Council Medical Research; and the Bill and Melinda Gates Foundation.

Ms Lindsay is a $\mathrm{PhD}$ candidate working on her dissertation in epidemiology and public health at the University of Maryland. Her research interest is international collaborations focusing on enteric diseases.

\section{References}

1. World Health Organization. Global burden of disease. Part 2. Causes of death [cited $2011 \mathrm{Feb} 8$ ]. http://www.who.int/healthinfo/global_ burden_disease/GBD_report_2004update_part2.pdf

2. Nair GB, Ramamurthy T, Bhattacharya MK, Krishnan T, Ganguly S, Saha DR, et al. Emerging trends in the etiology of enteric pathogens as evidenced from an active surveillance of hospitalized diarrhoeal patients in Kolkata, India. Gut Pathog. 2010;2:4. DOI: 10.1186/1757-4749-2-4

3. Mukherjee AK, Chowdhury P, Bhattacharya MK, Ghosh M, Rajendran K, Ganguly S, et al. Hospital-based surveillance of enteric parasites in Kolkata. BMC Res Notes. 2009;2:110. DOI: 10.1186/17560500-2-110

4. Nandi B, Nandy RK, Mukhopadhyay S, Nair GB, Shimada T, Ghose AC. Rapid method for species-specific identification of Vibrio cholerae using primers targeted to the gene of outer membrane protein OmpW. J Clin Microbiol. 2000;38:4145-51.

5. Chakraborty R, Sinha S, Mukhopadhyay AK, Asakura M, Yamasaki S, Bhattacharya SK, et al. Species-specific identification of Vibrio fluvialis by PCR targeted to the conserved transcriptional activation and variable membrane tether regions of the toxR gene. J Med Microbiol. 2006;55:805-8. DOI: 10.1099/jmm.0.46395-0

6. Nguyen TV, Le Van P, Le Huy C, Gia KN, Weintraub A. Detection and characterization of diarrheagenic Escherichia coli from young children in Hanoi, Vietnam. J Clin Microbiol. 2005;43:755-60. DOI: $10.1128 / \mathrm{JCM} .43 .2 .755-760.2005$

7. Pal A, Ghosh S, Ramamurthy T, Yamasaki S, Tsukamoto T, Bhattacharya SK, et al. Shiga-toxin producing Escherichia coli from healthy cattle in a semi-urban community in Calcutta, India. Indian J Med Res. 1999;110:83-5. 
8. Herring AJ, Inglis NF, Ojeh CK, Snodgrass DR, Menzies JD. Rapid diagnosis of rotavirus infection by direct detection of viral nucleic acid in silver-stained polyacrylamide gels. J Clin Microbiol. 1982;16:473-7.

9. Yan H, Yagyu F, Okitsu S, Nishio O, Ushijima H. Detection of norovirus (GI, GII), sapovirus and astrovirus in fecal samples using reverse transcription single-round multiplex PCR. J Virol Methods. 2003;114:37-44. DOI: 10.1016/j.jviromet.2003.08.009

10. Zerpa R, Huicho L. Intestinal coinfection with numerous Giardia trophozoites and Vibrio cholerae in hospitalized children with watery diarrhea. Wilderness Environ Med. 1995;6:167-72.

11. Ljungström I, Holmgren J, Svennerholm AM, Ferrante A. Changes in intestinal fluid and mucosal immune responses to cholera toxin in Giardia muris infection and binding of cholera toxin to Giardia muris trophozoites. Infect Immun. 1985;50:243-9.

12. Koh H, Baek SY, Shin JI, Chung KS, Jee YM. Coinfection of viral agents in Korean children with acute watery diarrhea. J Korean Med Sci. 2008;23:937-40. DOI: 10.3346/jkms.2008.23.6.937
13. Bilenko N, Levy A, Dagan R, Deckelbaum RJ, El-On Y, Fraser D. Does co-infection with Giardia lamblia modulate the clinical characteristics of enteric infections in young children? Eur J Epidemiol. 2004;19:877-83. DOI: 10.1023/B:EJEP.0000040533.75646.9c

14. Souza EC, Martinez MB, Taddei CR, Mukai L, Gilio AE, Racz ML, et al. Etiologic profile of acute diarrhea in children in São Paulo [in Portuguese]. J Pediatr (Rio J). 2002;78:31-8. DOI: 10.1590/S002175572002000100008

15. Grimprel E, Rodrigo C, Desselberger U. Rotavirus disease-impact of coinfections. Pediatr Infect Dis J. 2008;27:S3-10.

Address for correspondence: O. Colin Stine, 585 Howard Hall, $660 \mathrm{~W}$ Redwood St, University of Maryland School of Medicine, Baltimore, MD 21201, USA: email: ostin001@umaryland.edu

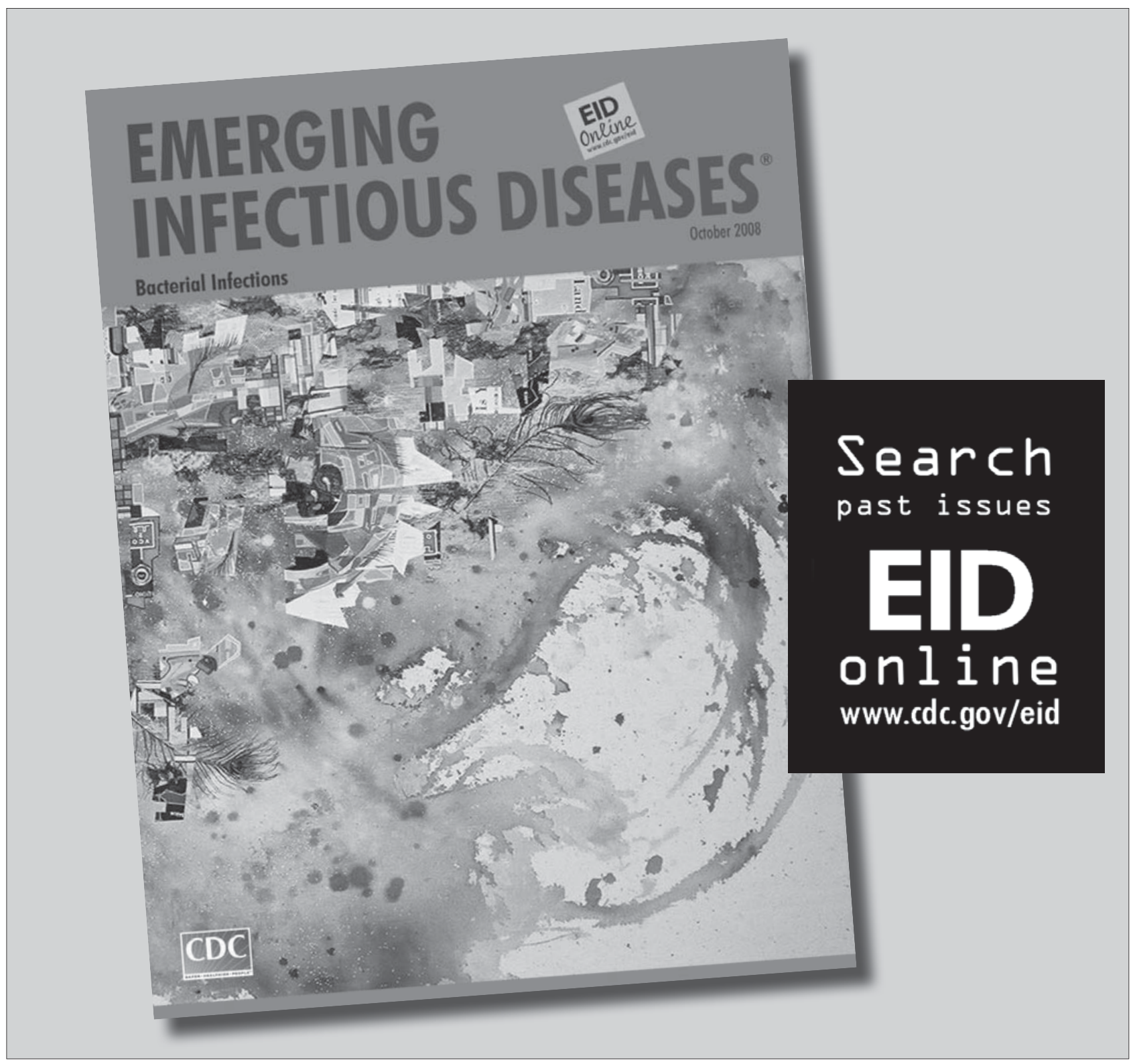

